\title{
DECISION AIDING IN PLASTIC SURGERY: A MULTICRITERIA ANALYSIS
}

\author{
Luiz Flávio Autran Monteiro Gomes ${ }^{1 *}$, Luís Alberto Duncan Rangel ${ }^{2}$ \\ and Priscila Pereira Fernandes ${ }^{3}$
}

Received November 19, 2009 / Accepted August 25, 2011

\begin{abstract}
The aim of this article is to present, through a real case, a practical way, based on Multicriteria Decision Aiding, to support decision making in Plastic Surgery. The case studied was a Caucasian woman of 36 years of age with mammarian hypertrophia with ptosis and abdominal lipodystrophy, making it necessary to select the most adequate techniques for the best aesthetic result. For this purpose, the multicriteria methods Even Swaps and PrOACT were used. Three plastic surgeons working in the city of Rio de Janeiro with equivalent professional experience were consulted as decision agents. In order to define the objectives to be achieved, the criteria relevant to the making of the decision and the alternatives which could be used were identified. Throughout this identification and in the later analysis the surgeons participated in the application of the methods, which contributed towards facilitating their acceptance of the multicriteria analysis in their decision making. It was confirmed, in this case study, that the use of Multicriteria Decision Aiding tends to make the medical decision more wide ranging and, above all, transparent. The plastic surgeons themselves validated the analysis, considering it fully consistent with their professional experience.
\end{abstract}

Keywords: Multicriteria Decision Aiding, Even Swaps, Plastic Surgery.

\section{INTRODUCTION}

The norms of conduct in Plastic Surgery constitute the central axis of medical attention. Thus, in the doctor-patient relationship one seeks patient satisfaction, in terms of their expectations of this from their perceived physical imperfections, as well as their concerns in regards to beauty in its functional-aesthetic condition. The administration of this speciality involves well-prepared preliminary work with a view to the most accurate objective. Here, psychology and technical

\footnotetext{
*Corresponding author

${ }^{1}$ Ibmec/RJ, Av. Presidente Wilson, 118, Sala 1110, Centro, 20030-020 Rio de Janeiro, RJ. E-mail: autran@ibmecrj.br

2 EEIMVR/PUVR/UFF, Av. dos Trabalhadores, 420, Vila Santa Cecília, 27255-125 Volta Redonda, RJ. E-mail: duncan@metal.eeimvr.uff.br

${ }^{3}$ Fundação Técnico Educacional Souza Marques, Av. Ernani Cardoso, 335, Sala dos Professores, Cascadura, 21310-310 Rio de Janeiro, RJ. E-mail: priscilafernandes@ig.com.br
} 
photography assume great importance. Psychology is used to profile the patient in a comprehensive and complex assessment, in regard to human personality and its weaknesses. Technical photography seeks to recognise imperfections, using medical documentation and the study of the surgical case as principles in the choice of the best-suited technique. The photographs must be completely clear and without grain, copied onto the best quality glossy paper. The ideal size is $16 \times 12 \mathrm{~cm}(6.3 \times 4.7$ inches $)$, larger ones being unnecessary, smaller ones being less clear (Franco \& Rebello, 1977).

Other factors that complement the framework of Plastic Surgery are anaesthesiology, which provides the surgeon with the support essential to his activity, the analysis of pre-operative tests and the evaluation of the patient's clinical condition, in addition to the care exercised by the surgeon in relation to dressings and bandages, which are concomitant to the post-surgical trauma skin physiotherapy, skill in which also complements the result of the surgery. However, the glamorous world of Plastic Surgery infects the individual with a desire to conquer beauty and he or she often cannot gauge that this is a surgical procedure which involves risks as in general surgery.

Nevertheless, when a plastic surgeon makes the decision to operate, he has already defined the main objective to be reached, the alternatives available and the risks of each technique and each patient. Therefore, this study aims to assist decision-making in the complex scenario of Plastic Surgery. Day-to-day, the plastic surgeon faces different clinical cases and different levels of uncertainty. Below are some real examples.

When faced with a case of ptosis (drooping breast) due to flaccidness of the breast skin, a doctor evaluated a 30 year-old Caucasian patient who showed this deformity after three pregnancies. The psychological dissatisfaction of the patient due to the unsightly appearance of the breasts was very apparent. The plastic correction of the defect was indicated through aesthetic bilateral mammoplasty. This was a clinical picture of low complexity in terms of the excellent health of the patient and also the simplicity of the defects that she carried.

In a case of severe abdominal lipodystrophy, characterised as the "abdominal apron", a 48 yearold Caucasian patient showed a voluminous mass of abdominal fat, the weight of which overloaded the spine producing pain in this area and difficulty in walking. This picture showed medium complexity, less due to the surgical technique to be applied and more due to the potential vascular insufficiency of the adipose tissue. The surgery itself, requires some degree of skill in regard to flap mobilisation during the preoperative, given that adipose tissue in great volume tends to be poor in terms of vascularisation and the detachment of the skin in the technique applied requires the need for preventive care so that it does not suffer a dramatic stretch, which may cause post-operative necrosis due to the deficient vascularisation.

In another patient, in a more complex situation, a 58 year-old Caucasian woman, hypertensive, overweight, with alterations in the electrocardiography tracing and a discrete left atrial overcharge, showed basal cell carcinoma on the right wing of the nose with destruction of the anatomical planes of the site and its surroundings. After photographs and pre-operative tests, the option for curative surgical treatment in two stages was selected. In the $1^{\text {st }}$ stage, there would be the 
use of the medium-frontal flap sliding technique. In the $2^{\text {nd }}$ stage, there would be the aesthetical correction of the contour of the nose wing with cartilage graft to shape up the alar neocartilage. It was opted for local anaesthetic infiltration, without constrictor vessel, of the frontal region and nasal dorsum up to the edge of the nose and cardiac monitoring.

As a result of the multiplicity of factors denoted in the illustration of the pathologies related here, it was sought to demonstrate the application of Multicriteria Decision Aid methods in Plastic Surgery decisions. By applying this tool it was hoped to bring benefits to decision-making in Plastic Surgery, because it allows the structuring of values that the surgeon previously only visualised and then decided.

The objective is to present the benefits of the tool of the Multicriteria Decision Aid, in particular the use of the PrOACT method (Hammond, Keeney \& Raiffa, 2004) combined with the Even Swaps technique as decision aiding in the field of Plastic Surgery. More specifically, through these tools, identification would be made, from among the possible mammoplasty and abdominalplasty techniques, of the most adequate techniques for the case studied.

In medicine as a whole, a doctor, on commencing the treatment of a patient in a critical condition, should think of how to react to possible complications and how the current treatment can facilitate or hinder alternative healing processes in the future. Though the science is ambiguous, information is limited, risks are high and, even so, decisions must be made safely and promptly (Gawande, 2002). Although there are various articles published on multicriteria decision making in Medicine (e.g. Gómez, Bielza, del Pozo \& Insua, 2007; Felli, Noel \& Cavazzoni, 2008; da Silva, Santos \& Borestein, 2009), none of these article approach problems in Plastic Surgery. In spite of the fact that most multicriteria decision making methods can be addressed to solving problems in Medicine, it did not seem feasible in the present case study to require formal representation of preferences by the decision agents that were interviewed. For this reason it was preferred to make use of a method of conjoint measurements in order to bypass that formalization (Bouyssou \& Pirlot, 2005).

Due to this complex scenario and the constant uncertainty faced by the plastic surgeon in his day-to-day work, offering him a view in the light of the Multicriteria Decision Aid system is certainly a very positive move, providing the professional with a transparent decision-making technique.

Therefore, in section 2 the theoretical basis of the applied methodology is presented and in Section 3 its application shown.

\section{THEORETICAL REFERENCES}

\subsection{Theoretical foundations of decision making}

A decision is the process that seeks to lead to a choice, from among different possible alternatives (Brown, 2005). Decisions have inspired the reflection of many thinkers, such as Aristotle and 
Plato, since the beginning of time. They discuss the human capacity to decide and claim that this possibility is what distinguishes us from other animals (Figueira, Greco \& Ehrgott, 2005).

Goodwin \& Wright (2000) understand that in no course of action can one reach the perfect alternative, where all objectives are reached, making it necessary in practice, to consider trade-offs among the benefits offered by the alternatives to elect the most satisfactory. The Multicriteria Decision Aid is a structured way of analysing problems with multiple criteria and alternatives (Mustajoki \& Hämäläinen, 2005). Its philosophy consists of extracting and utilising implicit information about the decision maker's preferences so as to help him, conducting him to his preferred solution (Wallenius et al., 2008). This science is likely to add to Plastic Surgery, bringing a more structured form to a complex scenario and therefore more transparency to decision-making. The challenge is in choosing a method that fits the profile of the plastic surgeons so that the tool can effectively bring its benefits to medicine.

The even swaps method is a Multicriteria Decision Aid method based on the value of trade-offs (Mustajoki \& Hämäläinen, 2005). This method will not make complex decisions become easy. It provides, however, a reliable mechanism and a coherent framework in which to make the swaps (Hammond, Keeney \& Raiffa, 1998). Moreover, the decision-maker, in this case the plastic surgeon, performs the values of the swaps and the swaps themselves. Thus, this method can give more credibility to the professional who, for the first time, will use another decision-making resource other than his or her own knowledge and experience.

The creators of this method begin from the premise that in order to simplify complex decisions one should start by simplifying the trade-offs. This is an appropriate method for dealing with decision problems, which involve various attributes without the possibility of a formal representation of preferences (Bouyssou \& Pirlot, 2005).

Smart Swaps is the software for the implementation of even swaps (Hämäläinen, 2003). This program helps the decision-maker with even swaps offering suggestions for alternatives that present practical dominance and presenting the attributes that can be candidates for the next swap, avoiding the need for the decision-maker to study the method in detail before applying it (Mustajoki \& Hämäläinen, 2005). This tool is available from the website http://www.smartswaps.hut.fi.

Goodwin \& Wright (2000) emphasise that, as one cannot totally eliminate the subjectivity that exists at the moment of decision, making it explicit will give greater transparency to the process. The PrOACT method helps observe all tangible and intangible aspects of the situation more clearly, translating all the facts, feelings, opinions, beliefs and guidelines under the best possible choice. Being a highly flexible method, it applies to any decision that needs to be taken. The premise of this method is to divide to conquer (Hammond, Keeney \& Raiffa, 2004).

The knowledge of the following concepts is of key importance for the understanding of this work:

i) Even Swaps - This technique provides a way of adjusting the consequences of several alternatives to represent them in an equivalent form in terms of a specific objective. As a 
result, this objective becomes irrelevant. The even swap increases the value of an alternative according to an objective, while it decreases the same value, in equivalent quantity, in relation to another. In essence, the even swaps method is a form of exchange - it forces one to estimate the value of one objective in accordance with another (Hammond, Keeney \& Raiffa, 2004).

ii) Pure Dominance - An alternative y is dominated by alternative $x$ if $x$ is at least as good in all attributes and is strictly better in at least one attribute (Bouyssou \& Pirlot, 2005).

iii) Practical Dominance - When an alternative y has only one advantage in comparison to another, it tends to be eliminated by practical dominance (Hammond, Keeney \& Raiffa, 2004).

iv) PrOACT - This method examines each step of the decision. The Problem, the Objectives, the Alternatives, the Consequences and the Trade-offs. Moreover, it also analyses the Uncertainties, the Tolerance and risks and the interlinked Decisions (Hammond, Keeney \& Raiffa, 2004).

Main participants involved in the practice of the Decision Theory: a) Decision-maker: the person responsible for making a choice (Brown, 2005); b) Analyst: the person that works collecting information and capturing knowledge (Belton \& Stewart, 2002); c) Facilitator: the person that presents skills in managing processes in groups (Belton \& Stewart, 2002).

\subsection{Medical decisions}

The first and most important step to achieve the desired success in the decision taken by the plastic surgeon, as in any medical practice, is the need to diagnose before treating.

In the first instance, the candidate for Plastic Surgery should be submitted to a thorough anamnesis, which will outline their complaints and the result sought. The plastic surgeon should be very careful about unrealistic claims, especially in cases where patients go so far as to show pictures of artists or models imagining that they may have the same body (Castro, 1997).

It is of paramount importance to analyse the psychological aspect and the mental attitude of a patient. It is this attitude that leads the clients to undergo intensive surgery, accepting it without fear, but with hope. The conscious or unconscious motivation that guides the client in search of aesthetic or reparative surgery justifies precaution on the part of the surgeon, whatever reasoning has been offered (Badim, 1971).

In addition to the usual systemic review of the patient, laboratory tests such as $\mathrm{CBC}$, glucose, urea, creatinine, uric acid, X-ray examinations, electrocardiogram and surgical risk are essential resources to guide treatment.

From an aesthetical point of view, in general, one observes the volume, the degree of deformity, the symmetry and biotype. The new body will be sculptured in a harmonious way with the curves and constitutional type of the patient. 
Having analysed all the data obtained and arriving at a precise diagnosis of the case, the moment is reached to opt for a determined surgical technique. Surgeons have to analyse the options, always acting with good sense. They should also opt for a technique that causes minimum complications, according to Castro (1997). The author concludes that the ideal technique, the one that should be chosen, is that which is, after thorough analysis, appropriate for the patient in the aesthetic, physiological and pathophysiological aspects. In addition, age should also be taken into account, because one should not opt for a wonderful aesthetic result in a 16 year-old in her mammoplasty reduction surgery, but one that almost annihilates her future chances of breastfeeding, adds Castro (1997).

And finally, it is recommended that the surgeon take his photographic documentation to the surgery room in order to make comparisons or as a possible aid to an unexpected decision he might have to make.

\subsection{Method framework}

The framework on which the even swaps method is based is joint measurement which refers to a set of tools and results developed by economists and psychologists in the early 60's, in order to provide measurement techniques that could be adapted to social sciences (Bouyssou \& Pirlot, 2005).

Bouyssou \& Pirlot (2005) add that, soon afterwards, people working in decision analysis noticed that joint measurement techniques could be used to structure preferences and, therefore, be employed in decision-making, because the threshold considered in the majority of the decision theory work is the binary relation $\succeq$ that means "at least as good as" among alternatives from a set $A$. The most obvious numerical representation is to associate a real number $V(a)$ to each $a \in A$ so that the comparison between these numbers reflects the original ratio $\succeq$.

It uses the following value function $V$ of $A$, according to equation (1):

$$
a \succeq b \Leftrightarrow V(a) \geq V(b)
$$

for every $a, b \in A$.

Whenever such numerical representation is possible we can use $V$ instead of $V(a)$ and use classic optimisation techniques to find the most preferable elements in $A$ given.

Conditions of this value function:

$$
\begin{aligned}
& -a \succeq b \text { or } b \succeq a \text { for every } a, b \in A \text { (complete); } \\
& -a \succeq b \text { and } b \succeq c, \text { so } a \succeq c \text { for every } a, b, c \in A \text { (transitive). }
\end{aligned}
$$

When $A$ is finite or accountably infinite these two options are not only necessary, but also enough to build a satisfactory value function.

When there is a satisfactory value function, it is not unique, it can undergo transformations such that $U$ and $V$ are satisfactory value functions of $A$, thus defining an ordinal scale. This ordinal 
scale although useful, does not allow a sophisticated analysis of the relationship $\succeq$ in the dialogue structure with the decision-maker. This is because the knowledge that $V(a) \leq V(b)$ is strictly equivalent to the knowledge that $a \succeq b$ and does not allow interference from the decision-maker in the use of transitivity.

When objects are evaluated according to their various dimensions, new possibilities emerge to obtain a numerical representation that specialise the original equation, (1). The purpose of the joint measurement is to study these models.

Given the $\succeq$ binary relationship of the product $X=X_{1} \times X_{2} \times \cdots \times X_{n}$ the joint measurement theory consists of finding conditions where it is possible to construct a convenient numerical representation in $\succeq$ and study the exclusivity of this representation. The core model is the additive value function below:

$$
x \succeq y \Leftrightarrow \sum_{i=1}^{n} v_{i}\left(x_{i}\right) \leq \sum_{i=1}^{n} v_{i}\left(y_{i}\right)
$$

Where is the real valuation of functions, also called partial value functions, $x=\left(x_{1}, x_{2}, \ldots, x_{n}\right)$ and $y=\left(y_{1}, y_{2}, \ldots, y_{n}\right)$.

Although the use of an additive model may seem arbitrary due to its restrictions, it can be seen as an advantage given the limitations of the cognitive abilities of humans. In addition, it is worth mentioning that this model can be reformulated to make the addition disappear.

If there are partial functions of value $v_{i}$, such that (2), it is clear that $V=\sum_{i=1}^{n} v_{i}$ is a value function that satisfies (1).

The even swaps technique is a simple way to perform the joint measurement method in decision problems involving many attributes where it is necessary to order the preferences of attributes and it is possible to make a joint measurement so that the objectives and their components are measured simultaneously under the same analytical viewpoint (Mustajoki \& Hämäläinen, 2005).

\section{CASE STUDY}

\subsection{Methodology}

A case study was carried out seeking to improve the quality of decision making of a plastic surgeon when using the PrOACT method in combination with the Even Swaps technique.

The reason for choosing this methodology as a research strategy is that the case study tries to clarify a decision or a set of decisions, the reason why they were taken, how they were implemented and with what results. It is also for the fact that it allows the examination of contemporary events without requiring control over behavioural events (Schramn, 1971 apud Yin, 2005). This is extremely opportune given the novelty of the study in question.

The exploratory study was based on informal interviews with Doctor Paulo Fernandes, a plastic surgeon with 30 years of experience, a graduate from the Rio de Janeiro Federal University in 1974, with residency in general surgery at the Carlos Chagas State Hospital, residency and 
specialisation in Plastic Surgery at the General Polyclinic of Rio de Janeiro - PGRJ and member of the Brazilian Academy of Anti-Aging Medicine. Based on his answers and much observation of his day-to-day work, a detailed analysis of his decisions was made in order to fit them into a new technology, the PrOACT and the Even Swaps technique in the execution of its functions, in an attempt to answer the following research question: How can the Multicriteria Decision Aid help a plastic surgeon in his decision-making?

In order to substantiate and validate the result obtained by the method, two more plastic surgeons were interviewed, both of equal experience; both of which took residency in Plastic Surgery and participate in international congresses and medical trips, remaining constantly up-to-date: Dr. Álvaro Cansanção, graduate from the Federal University of Bahia (UFBA) in 1968, with residency in general surgery from the UFBA at the Getúlio Vargas Hospital and residency in Plastic Surgery at Dr. Ivo Pitanguy's clinic and also a member of the Brazilian Plastic Surgery Society and Dr. Virmar Santana Ribeiro Soares, postgraduate in Plastic Surgery from the General Polyclinic of Rio de Janeiro where he is today the head of department. Dr. Virmar is a member of the Brazilian Plastic Surgery Society and of the Iberian Latin American Federation of Plastic Surgery.

The chosen Multicriteria Decision Aid methods were PrOACT and Even Swaps. While the first was used as a guide for the preparation of the even swaps process, this second method was chosen as it does not require a formal representation of preferences. As such, even swaps is one form of using conjoint measurements in multicriteria decision aiding (Bouyssou \& Pirlot, 2005). The definition of the problem in a clear form, the clear outlining of the objectives, of the alternatives and of the consequences facilitate the preparation of the tables of alternatives and consequences needed to carry out the even swaps.

The even swaps method allows one to focus on the work that is most important in decisionmaking, which is to decide on the real value of courses of action (Hammond, Keeney \& Raiffa, 1998). This method evaluates the possible options based on their relative importance (Cheung, Yiu \& Suen, 2004). The basis of the method is to make the alternatives become dominated and the attributes irrelevant through the valuation of trade-offs, in other words, the even swaps. These alternatives and attributes will be removed from analysis and the process will continue until only one alternative is left, which is the most desirable (Hämäläinen, 2003).

The Smart Swaps software, created in 2003 by the Finnish Hämäläinen and Mustajoki, based on PrOACT developed by Hammond, Keeney \& Raiffa, provides support for the implementation of even swaps, is freely available for academic purposes and is part of the decision aiding site Decisionarium (Mustajoki \& Hämäläinen, 2005).

On the first screen, it asks for details of the problem, and then it asks for the objectives and alternatives. The next stage consists of consequences, where the decision-maker measures each alternative according to each attribute. This valuation can be done with scales already established by the program or the user can create his or her own scale. The entire process is recorded, 
allowing the decision-maker to make a sensitivity analysis, going back to a point in the process and making new swaps and verifying if the same result occurs.

The software does not seek to provide a solution to the problem; all the values and their respective swaps are given by the decision-maker, the software only facilitates the process. The program automatically identifies the dominated alternatives and the irrelevant attributes. If the decisionmaker requests, it suggests new candidates available for the implementation of the new swaps, allowing the decision-maker to focus on judging the trade-offs. In addition, the software uses different colours to represent the ranking of alternatives for each attribute (Hämäläinen, 2003).

\subsection{Results}

An analysis was carried out of the clinical-surgical picture of a 36 year-old Caucasian patient, normolinea, who exhibited a high degree of discontent mainly due to the unsightly appearance of her breasts and her abdomen.

Asked about her complaints, the patient detailed her distress concerning what were once the harmonious aesthetics of her breasts and abdomen, which can be seen from her nipple-areola complexes (papillary), aesthetically preserved, and from her body contours.

She presented breasts with mild hypertrophy and ptosis, with visible asymmetry, and lipodystrophy of the lower deck of the abdomen, common deformities in multiparous women, but often insidious to emotional balance. As her complaints were considered justified, the patient underwent preoperative laboratory tests, namely high-resolution mammography and photographic documentation. Her breast skin showed good elasticity and an equitable proportion of adiposeglandular tissue, except in the left breast where the lipoid deformity was larger altering the volume and symmetry of the breast. This deformity was also prevalent in the abdomen.

The patient was considered to be in a condition to undergo surgery and it was then the moment to select an operating technique.

According to Strömbeck (1973), breast reduction is indicated in cases of hyper development of the breasts (macromastia or breast hypertrophy), when the skin, the gland and fat are reduced and in cases of ptosis when the skin is reduced in combination with lifting of the gland (mastopexy).

Ely (1980) writes that the evolution of the inverted " $T$ " technique for reductive mammoplasty arose from the G. Arié technique not going beyond the sub-mammarian groove. Strömbeck's markings are still in use without however, removing the upper pole cylinder, in what was the original technique of Lexer in 1912.

Meanwhile, D’Assumpção (1998) demonstrates his preference for reduction mammoplasties in "L" of Holander (1924), a technique evolved by Dufourmentel and Mouly in 1961, relating 100 cases presenting their experience with this technique, in order to produce smaller scars with very satisfactory results.

Among the techniques most employed for small and moderate mastoplasties are: Arié, Pitanguy, mammoplasty in "L" and periareolar mammoplasty (Resende, 2003). The many technical vari- 
ations demonstrate the importance of breasts in the female psyche and arise from the concern of the surgeon to perfect his technique with the aim of reducing the scar, giving adequate form, preserving the breast's physiology and the safety of the procedure.

From among the many techniques, the option was made to use the periareolar, originally performed by Kausch in 1916 for reduction mammoplasty in specific cases such as the one presented in the photographs with equally very satisfying results. However, one must highlight that in the majority of cases the inverted " $T$ " technique for reduction mammoplasty is the elected technique, as it would have been chosen by one of the interviewed surgeons. For this reason, while selecting PrOACT alternatives, the periareolar technique was chosen as it was the decision of the patient's operating surgeon and the inverted " $\mathrm{T}$ " as it was the technique most used and one which one could also have obtained success.

As regards the abdomen, the abdominoplasty or abdominal dermolipectomy performed for the first time by Dermars and Marx, in 1890 and Pitanguy in 1957, is also the elected technique for the aesthetic treatment of the abdominal gynoid lipodystrophies. However, in this case, the surgeon decided to operate performing the miniabdominalplasty of Elbaz and Flageul of 1971, combined with a liposuction created by Ives Gerard Illouz in 1977, since it would be limited to correcting small accumulations of fat and sagginess, with the consent of the other surgeons. Thus, the alternatives suggested by PrOACT to carry out the Even Swaps for the abdomen are abdominal dermolipectomy and miniabdominoplastly combined with liposuction.

Moreover, as the surgical techniques employed are options for localised or specific deformities, the Even Swaps method stands out when deciding on minority techniques, whose objectives are present in any surgical act, and are therefore comprehensive.

Through the interviews made, the PrOACT was prepared which led to the original even swaps table.

PrOACT Implementation:

i) Problem: Caucasian woman, 36 years-old, presenting breast hypertrophy with ptosis and abdominal lipodystrophy. To define what are the best mammoplasty and abdominoplasty techniques to correct the defects of the patient.

Objective: to achieve the best aesthetical result.

ii) Alternatives: Breasts: Inverted "T" technique (Pitanguy) or Periareolar Technique (Kausch).

iii) Abdomen: Total Abdominoplasty or Miniabdominalplasty with Liposuction. For the reasons above related.

iv) Consequences: The inverted " $T$ " technique for reduction mammoplasty allows the surgeon greater control of the operating field, increased mobility of action, allowing for the best shape to be given to the breasts, with respect to volume, in proportion to the body of the patient. 
The periareolar technique allows for an almost imperceptible scar to be made, however, it has the limitation of only allowing the handling of up to a certain volume of breast hypertrophy.

Abdominoplasty allows for comprehensive aesthetic correction. However, using this technique is an impediment for future surgery as there will be no flap or vascularisation for this.

The miniabdominoplasty with liposuction allows for future abdominoplasty surgery as it mobilises a flap below the navel.

v) Trade-offs: While in the inverted " $T$ " technique (Pitanguy) the surgeon has ample control over the operative field, which in turn gives him mobility to place the breasts in the volume and position as desired, the scar is larger than in the periareolar technique and the surgical trauma is also greater since this technique involves more manipulation.

Abdominoplasty combined with liposuction is a more limited technique but it presents smaller surgical trauma, a smaller scar and it allows for an abdominoplasty to be done in the future.

With this information, Table 1 was prepared for the implementation of even swaps with respect to Mammoplasty. In Table $1 \mathrm{~T} 1$ represents the inverted " $\mathrm{T}$ " technique and T2 represents the periareolar technique.

Table 2 displays the interactions involved in the implementation of the even swaps method.

Table 1 - Result of Scores for Mammoplasty.

\begin{tabular}{|l|c|c|c|c|c|c|}
\hline \multirow{2}{*}{ Objectives } & \multicolumn{2}{|c|}{ Dr. Paulo } & \multicolumn{2}{c|}{ Dr. Virmar } & \multicolumn{2}{c|}{ Dr. Álvaro } \\
\cline { 2 - 7 } & $\mathrm{T} 1$ & $\mathrm{~T} 2$ & $\mathrm{~T} 1$ & $\mathrm{~T} 2$ & $\mathrm{~T} 1$ & $\mathrm{~T} 2$ \\
\hline $\mathrm{O}_{1}-$ Aesthetic Result & 5 & 5 & 5 & 5 & 5 & 3 \\
$\mathrm{O}_{2}$ - Size of Incision & 3 & 5 & 3 & 5 & 4 & 5 \\
$\mathrm{O}_{3}$ - Surgical Trauma & 3 & 4 & 3 & 4 & 4 & 5 \\
$\mathrm{O}_{4}-$ Recovery Time & 3 & 3 & 3 & 3 & 4 & 4 \\
$\mathrm{O}_{5}-$ Difficulty of Surgery & 5 & 3 & 5 & 3 & 5 & 4 \\
$\mathrm{O}_{6}-$ Technique Limitation & 5 & 3 & 5 & 3 & 5 & 3 \\
\hline
\end{tabular}

Table 2 - Consolidated Result of the Even Swaps for Mammoplasty.

\begin{tabular}{|l|c|c|c|}
\hline Decision Agents & Dr. Paulo & Dr. Virmar & Dr. Álvaro \\
\hline Pre-analysis & $\mathrm{O}_{1}$ and $\mathrm{O}_{4}$ discarded & $\mathrm{O}_{1}$ and $\mathrm{O}_{4}$ discarded & $\mathrm{O}_{4}$ discarded \\
$1^{\text {st }}$ Swap & $\mathrm{O}_{3}$ with $\mathrm{O}_{5}$ & $\mathrm{O}_{2}$ with $\mathrm{O}_{5}$ & $\mathrm{O}_{3}$ with $\mathrm{O}_{5}$ \\
$2^{\text {nd }}$ Swap & $\mathrm{O}_{2}$ with $\mathrm{O}_{6}$ & $\mathrm{O}_{3}$ with $\mathrm{O}_{6}$ & $\mathrm{O}_{1}$ with $\mathrm{O}_{2}$ \\
Result & Periareolar & Periareolar & Inverted T \\
\hline
\end{tabular}


For the first two surgeons interviewed, the objectives 'Aesthetic Result' and 'Recovery Time' were discarded in the decision-making for mammoplasty as they presented the same scores for both the periareolar technique and the inverted " $T$ " technique. The third surgeon discarded the 'Recovery Time' objective for the same reason.

Having eliminated the irrelevant criteria, the first even swap made by Dr. Paulo was carried out between the pair of objectives 'Surgical Trauma' and 'Difficulty of Surgery'. To mitigate the 'difficulty of surgery' of the periareolar technique, from score 3 to score 5 , the plastic surgeon is willing to increase the 'surgical trauma' of this technique, lowering its score from 4 to 3 . The objective of changing the 'difficulty of surgery' score of the periareolar technique from 3 to 5 was to make it equal to the inverted " $T$ " technique so the objective would become irrelevant and it could be discarded. However, for this it was necessary to lower the score of the 'surgical trauma' objective in the periareolar technique which led to a draw for this objective as well and it was also discarded.

In the second swap, in order to improve the limitations of the periareolar technique from 3 to 5 and so discard that objective, the doctor is willing to increase the 'size of the incision' in this technique, lowering its score from 5 to 4 . In this way the 'technical limitations' objective was eliminated and it was concluded that the most intelligent decision was to use the periareolar technique because in the objective that is left, 'size of incision', the periareolar technique dominates the inverted " $T$ " technique, according to Dr. Paulo's scores.

In an interview with the second surgeon, the swaps for the choice of mammoplasty technique were begun with the pair of objectives 'Difficulty of Surgery' and 'Size of Incision'. To diminish the 'difficulty of surgery' of the periareolar technique raising its score from 3 to 5 , the plastic surgeon accepted an increase in the 'size of the incision', therefore lowering its grade from 5 to 4. Thus, the 'difficulty of surgery' objective was eliminated.

For the next swaps the pairs 'Technique Limitation' and 'Surgical Trauma' were chosen. To diminish the 'technique limitations' of the periareolar technique, raising its score from 3 to 5 , the plastic surgeon is willing to increase the 'surgical trauma' caused by surgical manipulation, lowering its score from 4 to 3 . With the draw generated by the implementation of these even swaps, two objectives were eliminated. Thus, having as a final result the dominance of the periareolar technique in the objective 'size of incision', the decision of Dr. Virmar is ratified.

In an interview with Dr. Álvaro, some scores diverged from the others, and regarding his decision-making, he would operate the breasts using the inverted " $\mathrm{T}$ " technique. According to his scores there was a draw in 'recovery time' and this objective was discarded.

Therefore, the process was started with the pair 'Difficulty of Surgery' and 'Surgical Trauma'. In order to diminish the 'difficulty of surgery' of the periareolar technique and thereby increase its grade from 3 to 5, the surgeon accepted an increase in the 'size of the incision' of this technique, lowering its grade from 5 to 4 . With the draw, both objectives are discarded. 
The second pair of swaps of Dr. Álvaro took place with the pair 'Aesthetic Result' and 'Size of Incision'. In order to improve the 'aesthetic result' of the periareolar technique and thereby increase its grade from 3 to 5, the surgeon accepted an increase in the 'size of incision' of this technique, lowering its grade from 5 to 4 . With the draw, the 'aesthetic result' and 'size of incision' were discarded, leaving the 'technique limitation' where the inverted " $T$ " technique dominates the periareolar technique. The result met the preferences of Dr. Álvaro, as he would not operate on the patient using the periareolar technique like the others, but with the inverted "T" technique. Table 3 shows the results from the implementation of the even swaps method for the Abdominoplasty. In Table $3 \mathrm{~T} 1$ represents Total Abdominal Dermolipectomy, and T2 represents Miniabdominoplasty with Liposuction.

Table 4 presents the consolidation of results for the abdominoplasty through the even swaps.

Table 3 - Result of Scores for Abdominoplasty.

\begin{tabular}{|l|c|c|c|c|c|c|}
\hline \multirow{2}{*}{\multicolumn{1}{|c|}{ Objectives }} & \multicolumn{2}{|c|}{ Dr. Paulo } & \multicolumn{2}{c|}{ Dr. Virmar } & \multicolumn{2}{c|}{ Dr. Álvaro } \\
\cline { 2 - 7 } & $\mathrm{T} 1$ & $\mathrm{~T} 2$ & $\mathrm{~T} 1$ & $\mathrm{~T} 2$ & $\mathrm{~T} 1$ & $\mathrm{~T} 2$ \\
\hline $\mathrm{O}_{1}-$ Aesthetic Result & 5 & 5 & 5 & 5 & 3 & 5 \\
$\mathrm{O}_{2}$ - Size of Incision & 4 & 5 & 4 & 5 & 3 & 5 \\
$\mathrm{O}_{3}$ - Surgical Trauma & 4 & 5 & 4 & 5 & 3 & 5 \\
$\mathrm{O}_{4}$ - Recovery Time & 3 & 4 & 3 & 4 & 3 & 5 \\
$\mathrm{O}_{5}-$ Difficulty of Surgery & 5 & 4 & 5 & 4 & 5 & 3 \\
$\mathrm{O}_{6}-$ Technique Limitation & 5 & 3 & 5 & 3 & 4 & 4 \\
\hline
\end{tabular}

Table 4 - Consolidated Result of the Even Swaps for Abdominoplasty.

\begin{tabular}{|c|c|c|c|}
\hline Decision Agents & Dr. Paulo & Dr. Virmar & Dr. Álvaro \\
\hline Pré-Análise & $\mathrm{O}_{1}$ Discarded & $\mathrm{O}_{1}$ Discarded & $\mathrm{O}_{6}$ Discarded \\
\hline $1^{\text {st }}$ Swap & $\mathrm{O}_{3}$ with $\mathrm{O}_{5}$ & $\mathrm{O}_{2}$ with $\mathrm{O}_{5}$ & \multirow{2}{*}{$\begin{array}{c}\text { Practical Dominance of } \\
\text { Mini Abdominoplasty } \\
\text { + Lipo }\end{array}$} \\
\hline $2^{\text {nd }}$ Swap & $\mathrm{O}_{2}$ with $\mathrm{O}_{6}$ & $\mathrm{O}_{3}$ with $\mathrm{O}_{6}$ & \\
\hline Result & $\begin{array}{l}\text { Mini Abdominoplasty } \\
+ \text { Lipo }\end{array}$ & $\begin{array}{l}\text { Mini Abdominoplasty } \\
\text { +Lipo }\end{array}$ & $\begin{array}{l}\text { Mini Abdominoplasty } \\
\text { +Lipo }\end{array}$ \\
\hline
\end{tabular}

With the scores given to the decision-making objectives regarding the abdominoplasty, Dr. Paulo and Dr. Virmar discarded the 'Aesthetic Result' objective and Dr. Álvaro discarded 'Technique Limitations'. It is worth noting that all three surgeons were unanimous in choosing miniabdominoplasty combined with liposuction as the elected technique.

The first surgeon interviewed, Dr. Paulo, started his swaps with the pair of objectives 'Difficulty of Surgery' and 'Surgical Trauma'. In order to minimise the 'difficulty of surgery' of a miniabdominoplasty combined with liposuction, improving its score from 4 to 5 so that this objective 
becomes irrelevant and is consequently dismissed, the plastic surgeon accepted an increase in the 'surgical trauma' of this technique, lowering its score from 5 to 4 . In this way, the 'difficulty of surgery' was eliminated through the procedure suggested by the even swaps technique and the 'surgical trauma' objective also discarded, since by doing the swaps there was a draw, making this objective irrelevant.

The new swaps were carried out with the pair of objectives 'Technique Limitation' and 'Size of Incision'. To improve the 'technique limitation' of the miniabdominoplasty technique combined with liposuction, changing its score from 3 to 5 , the plastic surgeon accepted an increase in the 'size of the incision' lowering its score from 5 to 4, resulting in a draw. Having dismissed the drawn objectives, only 'time of recovery' remained, where the miniabdominoplasty technique combined with liposuction dominated the abdominoplasty total confirming the decision of Dr. Paulo.

To accomplish the swaps suggested by Dr. Virmar for the choice of abdominoplasty technique and to perform surgery in the abdomen, the initial dominance was eliminated and the swaps began with the pair of objectives 'Difficulty of Surgery' and 'Size of Incision'. In order to diminish the 'difficulties of surgery' of the miniabdominoplasty technique combined with liposuction, raising its score from 4 to 5 , the surgeon agreed to increase the 'size of incision' performed in this technique, lowering its score from 5 to 4 . Thus, two objectives were eliminated at the same time, as there was a draw.

Next, the even swap was carried out between the pair 'Technique Limitation' and 'Surgical Trauma'. At this point, the plastic surgeon made the change of a decrease in the 'technique limitations' of the miniabdominoplasty with liposuction, increasing its score from 3 to 5, for an increase in 'surgical trauma', lowering its score from 5 to 4 . Once more this resulted in a draw, with the elimination of both objectives, with only the 'time of recovery' objective remaining where the miniabdominoplasty technique combined with liposuction has dominance.

After the elimination of the objective initially discarded by Dr. Álvaro, namely, 'Technique Limitation', it was observed that, for Dr. Álvaro, miniabdominoplasty combined with liposuction is more advantageous in four objectives, presenting a small disadvantage in the difficulty of surgery' which, according to him, does not outweigh the other disadvantages. It was concluded that, in practical terms, miniabdominoplasty with liposuction dominated total abdominal dermolipectomy and that in one of the objectives it had an advantage, which for Dr. Álvaro was not very significant.

\subsection{Validation of results}

Both techniques for mammoplasty and abdominoplasty presented, on balance, perfectly good conditions for being used and providing excellent aesthetic results, resolving the patient's problem in a satisfactory way. In Plastic Surgery, decisions are made on the details. So that a technique can be chosen, it normally presents in all its attributes, a nominal scale that varies from excellent to bad (excellent - very good - good - regular - bad), minimum score "good". In this 
way, the classifying level between them is very close, requiring an even swaps method that is well structured and for the swaps to be carried out in a very meticulous way.

Even so, the method presented the result that the plastic surgeon doctors believe to be the most indicated for the case studied, including being able to understand the divergent preferences of one of the surgeons giving in his even swaps a result that was most adequate to his opinion. It was seen that the use of the decision aiding system produces a more transparent decision, once all the objectives are measured and the swaps carried out in an even way. The plastic surgeons themselves validated the method, considering the method precise and coherent with the techniques, presenting such a fair classifying level.

\section{FINAL COMMENTS AND DISCUSSION}

The results obtained were presented and discussed with the plastic surgeons that served as decision agents in this study. They felt secure with the use of the multicriteria approach and confident about the results. Based on the large experience of these surgeons, they felt trustful enough to be able to use the same approach in similar cases. They concluded that their practices in Plastic Surgery can be in many complex situations complemented by the use of the multicriteria approach.

This work sought to introduce the multicriteria decision aiding as decision support in Plastic Surgery. As mentioned in section 1 of this article, the application of multicriteria decision aiding to Plastic Surgery has been by far an area untouched in the medical decision making literature. The use of the PrOACT tool and Even Swaps were proposed for the solution of a specific problem which was the choice of the best surgical techniques for breast and abdomen in the aesthetic correction of a patient with breast hypertrophy and ptosis and abdominal lipodystrophy. During the study, several analyses were conducted, aiming to demonstrate the applicability and efficiency of the methods employed.

Among the many Multicriteria Decision Aiding methods, it was necessary to choose one that would bring total transparency to the analysis and make the participation of the plastic surgeon possible so that they would become receptive to this new technology in the decision making process. This is why these two methods were chosen. These are simple methods that contribute in practice to adequate decision-making. Both PrOACT and the Even Swaps were performed with the full participation of the doctors, they being responsible for the value range of each attribute, as well as, granting permission for making the swaps, being fully in agreement with each step of the process.

The main objective of the study was not to provide a single solution through the Multicriteria Decision Aiding method but to give more transparency to the decision, giving more clarity concerning the goals and alternatives available, serving as the name itself says, as decision aiding for the plastic surgeon. This objective was reached, with the method receiving full approval from the professionals interviewed, who may even use it in future decisions. 
It is worth noting that the methods employed aggregate in the sense of giving more transparency to the preferences of plastic surgeons, allowing their participation in all stages of the decisionmaking process. However, the essential objective of such methods is effectively to support real decision-making processes and not to eliminate potential personal biases that may exist.

Plastic Surgery is a medical sub-specialty that originated from General Surgery in that it emphasises the healing (Reconstructive Plastic Surgery) and the aesthetic of forms (Aesthetic Plastic Surgery), and which, therefore, obeys the same medical standards of all surgery, essentially bringing the art of composing beauty in its various technical-operational possibilities.

The technical nuances employed on the patients themselves that would not be capable of modelling through the even swaps method and its complements, are part of the surgical strategies used during the surgery and relate to small technical variations possible in the course of the surgery (always within the strict rigour of medical science and in benefit of the patient), are part of the experience of the surgeon and drawn from knowledge gained. The pre-operative evaluation and surgical risk are part of the routine medical procedures for the surgical patient in a general way and, are therefore excluded from these comparisons.

Thus it is believed that the method in question has been grounded on goals of wide-ranging value, present in each and any Plastic Surgery to lead to the best decision.

\section{ACKNOWLEDGMENTS}

The authors are grateful to the referees for their insightful comments on the first version of this article. They are also grateful to the plastic surgeons interviewed for supplying information which was indispensable for carrying out the work. This work was partially supported by CNPq through Research Projects No. 310603/2009-9 and 502711/2009-4.

\section{REFERENCES}

[1] BADIM J. 1971. Introdução à Cirurgia Plástica. Livraria Atheneu, Rio de Janeiro.

[2] Belton V \& Stewart TJ. 2002. Multiple Criteria Decision Analysis. An integrated Approach. Kluwer Academic Publishers, Massachusetts.

[3] Bouyssou D \& Pirlot M. 2005. Conjoint Measurement Tools for MCDM. In: Multiple Criteria Decision Analysis: State of the art surveys, edited by Figueira J, Greco S \& Ehrgott M, Springer, New York.

[4] BROWn RV. 2005. Rational choice and judgment: decision analysis for the decider. John Wiley \& Sons, New Jersey.

[5] Castro O. 1997. Princípios e Prioridades em Cirurgia Plástica. Fundo Editorial BYK, São Paulo.

[6] Cheung S, Yiu KTW \& Suen H. 2004. Construction Negotiation Online. Journal of Construction Engeneering and Management, 130(6), December, p. 844-852.

[7] D’AssumpÇão EA. 1998. Contribuição à mamaplastia redutora em L. Revista da Sociedade Brasileira de Cirurgia Plástica, 13(1): Jan./April, p. 51-60. 
[8] Da Silva MEM, Santos ER \& Borenstein D. 2010. Implementing Regulation Policy in Brazilian Health Care Regulation Centers. Medical Decision Making, 30(3): 366-379.

[9] Ely JF. 1980. Cirurgia Plástica. 2 ed. Guanabara Koogan, Rio de Janeiro.

[10] Felli JC, Noel RA \& Cavazzoni PA. 2009. A Multiattribute Model for Evaluating the BenefitRisk Profiles of Treatment Alternatives. Medical Decision Making, 29(1): 104-115.

[11] Figueira J, Greco S \& Ehrgott M. 2005. Introduction. In: Multiple Criteria Decision Analysis: State of the art surveys, edited by Figueira J, Greco S \& EhrGotT M, Springer, New York.

[12] Franco T \& Rebello C. 1977. Cirurgia Estética. Livraria Atheneu, Rio de Janeiro.

[13] Gawande A. 2002. Complicações: Dilemas de um cirurgião diante de uma ciência imperfeita. Objetiva, Rio de Janeiro.

[14] Gómez M, Bielza C, Del Pozo JAF \& Insua SR. 2007. A Graphical Decision-Theoretic Model for Neonatal Jaundice. Medical Decision Making, 27(3): 250-265.

[15] Goodwin P \& Wright G. 2000. Decision Analysis for Management Judgment. John Wiley \& Sons, Chichester.

[16] HÄMÄLÄINEN RP. 2003. Decisionarium - Aiding Decisions, Negociating and collecting opinions on the web. Journal of Multicriteria Decision Analysis, 12: 101-110.

[17] Hammond JS, Keeney R \& Raiffa H. 1998. Even Swaps: A rational method for making tradeoffs. Harvard Business Review, 76(2): 137-148.

[18] Hammond JS, Keeney R \& RaIfFa H. 2004. Decisões Inteligentes: somos movidos a decisões como avaliar alternativas e tomar a melhor decisão. Campus, Rio de Janeiro.

[19] Mustajoki J \& HäMÄLÄINEN RP. 2005. A preference programming approach to make the even swaps method even easier. Decision Analysis, 2(2): June, p. 110-123.

[20] Resende JHC. 2003. Perguntas e Respostas de Cirurgia Plástica. $2^{\text {nd }}$ ed. Rubio, Rio de Janeiro.

[21] Strömbeck JO. 1973. Reduction Mammoplasty. In: Plastic Surgery: A concise guide to clinical practice by 53 authors, edited by GRABB WC \& SMITH JW, $2^{\text {nd }}$ ed. Library of Congress, Washington, p. 955-972.

[22] Wallenius J, Dyer JS, Fishburn PC, Steuer RE, Zionts S \& Deb K. 2008. Multiple Criteria Decision Making, Multiattribute Utility Theory: Recent Accomplishments and What Lies Ahead. Management Science, 54(7): July, p. 1336-1349.

[23] Yin RK. 2005. Estudo de Caso: planejamento e métodos. 3 ed. Bookman, Porto Alegre. 